\title{
BMJ Open The impact of weight misperception on health-related quality of life in Korean adults (KNHANES 2007-2014): a community-based cross-sectional study
}

\author{
Susan Park, ${ }^{1}$ Sejin Lee, ${ }^{2}$ Jinseub Hwang, ${ }^{3}$ Jin-Won Kwon ${ }^{4}$
}

To cite: Park S, Lee S, Hwang J, et al. The impact of weight misperception on healthrelated quality of life in Korean adults (KNHANES 2007-2014): a community-based crosssectional study. BMJ Open 2017;7:e016098. doi:10.1136/ bmjopen-2017-016098

- Prepublication history and additional material for this paper are available online. To view these files please visit the journal online (http://dx.doi. org/10.1136/bmjopen-2017016098).

Received 25 January 2017 Revised 11 May 2017 Accepted 25 May 2017

\section{(a) CrossMark}

${ }^{1}$ Institute of Health and Environment, Seoul National University, Seoul, South Korea ${ }^{2}$ Department of Health Policy and Management, Gillings School of Global Public Health, University of North Carolina, Chapel Hill, North Carolina, USA ${ }^{3}$ Department of Computer Science and Statistics, Daegu University, Gyeongsan-si, South Korea

${ }^{4}$ College of Pharmacy and Research Institute of Pharmaceutical Sciences, Kyungpook National University, Daegu, South Korea

Correspondence to Prof Jin-Won Kwon; jwkwon@ knu.ac.kr

\section{ABSTRACT}

Background/objectives Weight perception, especially misperception, might affect health-related quality of life (HRQoL); however, related research is scarce and results remain equivocal. We examined the association between HRQoL and weight misperception by comparing obesity level as measured by body mass index (BMI) and weight perception in Korean adults.

Methods Study subjects were 43883 adults aged 19 years or older from cycles IV (2007-2009), V (2010-2012) and VI (2013-2014) of the Korean National Health and Nutrition Examination Survey. Multiple regression analyses comprising both logit and tobit models were conducted to evaluate the independent effect of obesity level as measured by BMI, weight perception and weight misperception on HRQoL after adjusting for demographics, socioeconomic status and number of chronic diseases. We also performed multiple regressions to explore the association between weight misperception and HRQoL stratified by BMI status.

Results Obesity level as measured by BMI and weight perception were independently associated with low $\mathrm{HRQ} \mathrm{L}$ in both separate and combined analyses.

Weight misperception, including underestimation and overestimation, had a significantly negative impact on HRQoL. In subgroup analysis, subjects with BMI ranges from normal to overweight who misperceived their weight also had a high risk of low HRQoL. Overestimation of weight among obese subjects associated with low HRQoL, whereas underestimation of weight showed no significant association.

Conclusions Both obesity level as measured by BMI and perceiving weight as fat were significant risk factors for low HRQoL. Subjects who incorrectly perceived their weight relative to their BMI status were more likely to report impaired $\mathrm{HRQOL}$, particularly subjects with $\mathrm{BMI}$ in the normal to overweight range. Based on these findings, we recommend political and clinical efforts to better inform individuals about healthy weight status and promote accurate weight perception.

\section{INTRODUCTION}

Obesity has been a public health concern owing to its rapidly increasing prevalence and deleterious health effects in both developed and developing countries. ${ }^{1}$ A large

\section{Strengths and limitation of this study}

A strength of this study is that it is the firstAsian study to investigate the impact of weight misperception on health-related quality of life (HRQoL) for all body mass index ranges.

- This study revealed the significant effect of weight misperception on HRQoL after adjusting for age, chronic diseases and socioeconomic status.

- Nationally representative data with a large sample size.

- The cross-sectional design and unmeasured confounding factors limit causal inferences from our results.

number of studies indicate that obesity is an important risk factor for various physical health problems, including type 2 diabetes, cardiovascular disease, stroke and cancer. ${ }^{2}$ Harmful effects of obesity on psychological health conditions, such as stress, ${ }^{3}$ depression ${ }^{4}$ and certain mental illness, ${ }^{5}$ have also been observed. The medical problems associated with obesity have a major impact on public health; obesity also affects individuals' functional capacity to lead active lives. ${ }^{6}$

Health-related quality of life (HRQoL) can be an appropriate health outcome to use in evaluating these multifaceted effects of obesity on both physical and psychosocial health. Over the past few decades, epidemiological studies have revealed a significant association between obesity and impaired HRQoL, showing a dose-response relationship between HRQoL impairment and increase in body mass index (BMI).${ }^{67}$ Furthermore, studies of patients undergoing bariatric surgery consistently found that weight loss was associated with improvement in HRQoL. ${ }^{8}$ These findings support the hypothesis that prevention and treatment of obesity are important to improve HRQoL. 
Misperception of weight status has been reported as an obstacle to escape from obesity. People with obesity who perceive their weight as normal tend to have a lower desire to control their weight, ${ }^{10}$ engage in fewer attempts to lose weight, ${ }^{10}{ }^{11}$ exhibit poor diet habits ${ }^{12}$ and engage in less physical activity. ${ }^{10}{ }^{13}$ Similarly, people with normal weight who perceive their weight as obese are more likely to engage in unhealthy weight control activities, ${ }^{14}{ }^{15}$ have a greater risk of obesity ${ }^{16} 17$ and experience psychological distress. ${ }^{18}{ }^{19}$ Unfortunately, perceived weight status is often discordant with actual body weight. According to previous studies from the USA and Canada, the proportions of weight misperception were approximately $20 \%$ and $30 \%$ among men and women, respectively. ${ }^{20}{ }^{21}$ Recent Korean studies reported that approximately $40 \%$ of the total study population incorrectly perceived their weight status when compared with actual BMI status, ${ }^{22}$ which indicates a substantial difference in weight misperception across countries. This difference may be due to variations in sociocultural background and obesity prevalence, which may affect weight misperception. ${ }^{23} 24$

Weight misperception might have a harmful impact on HRQoL when taking into consideration the substantial evidence regarding the adverse effect of weight misperception on health behaviours and psychological health. However, only a few studies have examined the association between weight misperception and HRQoL, and the findings have been inconsistent. For example, some studies found that subjects who overestimated their weight status showed a significantly lower HRQoL than those who accurately perceived their weight. ${ }^{25-27}$ In contrast, other studies reported that subjects who underestimated or overestimated their weight status reported higher HRQoL. ${ }^{27}{ }^{28}$ In addition, there is a bias in the literature towards Western study populations, particularly adolescents and young adults, which presents a challenge in generalising the findings to an Asian adult population. The long-term harmful effects of weight misperception on physical health can be underestimated in younger individuals, because obesity-related health problems frequently do not become apparent until midlife.

In the present study, we explored the pattern of weight misperception by comparing BMI level and weight perception among the Korean adult population. Furthermore, we examined the impact of obesity level as measured by BMI, weight perception and weight misperception on HRQoL.

\section{METHODS}

\section{Data/sample}

The data analysed in this study were obtained from cycles IV (2007-2009), V (2010-2012) and VI (2013-2014) of the Korean National Health and Nutrition Examination Survey (KNHANES). KNHANES was established and is managed by the Korea Centers for Disease Control (KCDC) to assess the health and nutrition status of the population and provide basic statistics for health policy development for the Korean population. The original data are available to the public through the website of the KCDC. The study design and data collection methods were approved by the research ethics committee of the KCDC. KNHANES data were obtained by complex, multistage, probability sampling to be representative of the civilian, non-institutionalised Korean population. For example, in the 2011 survey, the design involved two stages: (1) selecting a sample of 192 primary sampling units (PSUs) among approximately 200000 PSUs for the whole country; and (2) systematic sampling of 20 households among each PSU that consisted of an average of 60 households. Finally, all individuals in the selected households were targeted for the survey. ${ }^{29}$ Since 2007 , KNHANES has been conducted every year based on a rolling sample survey, rather than the periodic survey that had been administered in the past. One cycle comprises 3 years of rolling samples; two or more cycles can be combined for analysis. In the present study, we combined three survey cycles to overcome the limitation of the small sample size of subjects with severe obesity. We limited our analysis to subjects aged 19 years or older (18406 in KNHANES IV, 19599 in V and 12089 in VI) because EuroQol five dimensions questionnaire (EQ-5D) were only administered to adults. We also excluded pregnant women and respondents with missing BMI, EQ-5D or covariate data. Finally, a total of 43883 subjects were included in this study. The demographic distributions of final study subjects were similar to those in the original KNHANES data. ${ }^{29}$

\section{Measures}

HRQoL was assessed using a Korean version of EQ-5D. EQ-5D is a widely used generic HRQoL instrument, and the validity of the Korean version was successfully demonstrated in a previous study. ${ }^{30}$ The instrument consists of five dimensions: mobility, self-care, usual activities, pain/discomfort and anxiety/depression. The scores of a completed EQ-5D can be converted into a single summarised index score using a value set obtained through the time trade-off valuation method. Although various value sets are available, the value set we applied was derived from a representative Korean sample, ${ }^{31}$ and officially used for reporting KNHANES by the KCDC. The EQ-5D index score represents health status on a continuum from 0 to 1 ; a higher index score indicates better health status. We defined low HRQoL as the lowest quintile of EQ-5D index score and the cut-off point as 0.867 because we observed a notable decline under $20 \%$ of the score in this population. The previous Korean studies also used the same cut-off point for low HRQoL. ${ }^{32-34}$

Anthropometric data (ie, height and weight) in KNHANES were measured by trained nurses using a standardised procedure. BMI was calculated as weight $(\mathrm{kg}) /$ height $\left(\mathrm{m}^{2}\right)$ and categorised into four levels based on Asian criteria for obesity, ${ }^{35}$ including underweight $\left(<18.5 \mathrm{~kg} / \mathrm{m}^{2}\right)$, normal/overweight $\left(18.5-<25 \mathrm{~kg} / \mathrm{m}^{2}\right)$, obesity $\left(25-<30 \mathrm{~kg} / \mathrm{m}^{2}\right)$ and severe obesity $\left(\geq 30 \mathrm{~kg} / \mathrm{m}^{2}\right)$. 
Weight perception was assessed with a self-reported questionnaire. The participants were asked 'What do you think about your shape?' and responded 'very thin', 'somewhat thin', 'normal', 'somewhat fat' or 'very fat'. The responses of thinness (very and somewhat) were combined into one level for matching with the BMI categories. We created a variable with two values (underestimation and overestimation) to classify weight perception compared with obesity level as measured by BMI to represent discordance between weight perception and BMI. We matched the BMI ranges from normal to overweight $(18.5-<25 \mathrm{~kg} /$ $\mathrm{m}^{2}$ ) to the normal of weight perception according to previous Korean studies on weight misperception. ${ }^{22} 3637$

We considered the time of survey cycles (KNHANES IV, V and VI), demographics, socioeconomic status and comorbidity of chronic disease as covariates. The number of chronic diseases was calculated based on self-reported medical history of the following diseases diagnosed by a physician: diabetes, hypertension, hyperlipidaemia, cancers (gastric cancer, liver cancer, lung cancer, colon cancer, breast cancer and uterine cancer), pulmonary diseases (asthma, tuberculosis, rhinitis, chronic obstructive pulmonary disease), cardiovascular diseases (stroke, angina/myocardial infarction), thyroid disease, arthritis, renal failure, hepatitis and liver cirrhosis.

\section{Statistical analysis}

We calculated the unweighted frequencies and weighted proportions with SEs to present the general distributions of demographics, socioeconomic status, number of chronic diseases, obesity level by BMI and weight perception. The proportions of low HRQoL according to obesity level as measured by BMI, weight perception and weight misperception were estimated. These proportions are presented by survey cycle to confirm the data stability of the EQ-5D index score across the time of the survey. The percentages of agreement between the obesity level by BMI and the weight perception were calculated, and overall agreement was evaluated using the Kappa statistic.

Multiple regression analyses comprising both binary and linear models were performed to evaluate the effects of BMI, weight perception and weight misperception on low HRQoL after adjusting for various covariates. Low HRQoL was analysed with a binary logit model. Tobit regression modelling was performed to analyse the full EQ-5D index score taking into account right censoring of the score. First, we performed separate regressions for BMI, weight perception and weight misperception to evaluate the respective effects of these variables on HRQoL. We then explored the association between weight misperception and HRQoL after stratification by BMI category. All regression models were adjusted for demographics, socioeconomic status and number of chronic diseases to control the possible confounding effects.

The complex sampling design and sample weights for combining survey cycles were taken into account in all analyses. Analyses were conducted with SAS V.9.4 and STATA V.11.

\section{RESULTS}

The distribution of demographics, obesity level by BMI, weight perception and HRQoL are presented in table 1. Based on BMI criteria, $60.5 \%$ of men and $66.0 \%$ of women had normal weight. The percentages of subjects who believed their weight to be normal were $39.5 \%$ and $40.6 \%$ for men and women, respectively. These values were much lower than the percentages of subjects who were actually of normal weight. While the prevalence of obesity was higher in men than in women, the proportion of men perceiving their weight as fat was lower than in women. Generally, women presented with a higher prevalence of chronic diseases and lower HRQoL compared with men.

As shown in table 2, 39.4\% of men and $43.2 \%$ of women misperceived their weight. Although the proportion of misperception was similar in both sexes, the type for misperception was different between men and women. Men were more likely to underestimate their weight compared with women $(27.2 \%$ of men and $15.6 \%$ of women); in contrast, women were more likely to overestimate their weight (12.2\% of men, $27.6 \%$ of women). The subjects with normal weight according to BMI reported the highest weight misperception in both sexes. Overall agreement between the obesity level by BMI and the weight perception status was fair in both sexes (kappa coefficient men $=0.38$; women $=0.32$ ).

Figure 1 shows the prevalence of low HRQoL according to BMI level, weight perception and weight misperception by survey cycle and sex. All survey cycles showed similar proportions of low HRQoL according to BMI and weight perception status. The mean, median and quartile distributions of EQ-5D index score according to BMI, weight perception and weight misperception are also presented in online supplementary table 1 . For men, the proportion of low HRQoL was slightly higher in the subjects with underweight or severe obesity by BMI than in those with normal BMI. The same association pattern was observed for weight perception status. For women, the proportion of low HRQoL increased with BMI. Higher prevalence of low HRQoL was observed in the subjects who perceived their weight as underweight or (somewhat/very) fat compared with those who perceived their weight as normal, in both sexes. Regarding weight misperception, subjects who underestimated their weight were more likely to report low HRQoL than those who perceived their weight accurately, a pattern seen more obviously in women than in men. This trend was not observed in subjects who overestimated their weight, but these individuals were also more likely to report low HRQoL after adjustments (data shown in table 3 ).

Table 3 presents the results of logit and tobit models for HRQoL according to BMI level, weight perception and misperception in the univariate and multiple regression analyses. In the binary model of multivariable analysis, the ORs of low HRQoL were higher in underweight or obese subjects according to BMI than in those with normal weight. Women also had higher ORs of low HRQoL in 
Table 1 General distribution of socioeconomic status, chronic disease, obesity level by BMI, weight perception and HRQoL by sex

\begin{tabular}{|c|c|c|c|c|}
\hline & \multicolumn{2}{|c|}{$\begin{array}{l}\text { Men } \\
(n=18602)\end{array}$} & \multicolumn{2}{|c|}{$\begin{array}{l}\text { Women } \\
(n=25281)\end{array}$} \\
\hline & $\mathbf{N}^{*}$ & $\%$ (SE)† & $\mathbf{N}$ & $\%$ (SE) \\
\hline \multicolumn{5}{|l|}{ Survey cycle } \\
\hline KNHANES IV (2007-2009) & 6981 & $33.0(0.5)$ & 9408 & $32.5(0.5)$ \\
\hline KNHANES V (2010-2012) & 7370 & $40.7(0.6)$ & 10005 & $40.9(0.5)$ \\
\hline KNHANES VI (2013-2014) & 4251 & $26.4(0.5)$ & 5868 & $26.7(0.4)$ \\
\hline \multicolumn{5}{|l|}{ Age } \\
\hline $19-40$ & 5719 & $42.3(0.6)$ & 7870 & $38.3(0.5)$ \\
\hline $40-59$ & 6915 & $40.4(0.5)$ & 9434 & $39.7(0.4)$ \\
\hline $60+$ & 5968 & $17.4(0.3)$ & 7977 & $22.0(0.4)$ \\
\hline \multicolumn{5}{|l|}{ Education } \\
\hline Elementary school & 3424 & $12.2(0.3)$ & 8208 & $24.9(0.4)$ \\
\hline Middle school & 2226 & $10.0(0.3)$ & 2593 & $10.0(0.2)$ \\
\hline High school+ & 12952 & $77.8(0.4)$ & 14480 & $65.1(0.5)$ \\
\hline \multicolumn{5}{|l|}{ Equivalised household incomeł } \\
\hline $1 \mathrm{~T}$ & 5931 & $26.8(0.5)$ & 9002 & $31.6(0.5)$ \\
\hline $2 \mathrm{~T}$ & 6376 & $36.2(0.5)$ & 8248 & $34.6(0.5)$ \\
\hline $3 T$ & 6295 & $37.1(0.6)$ & 8031 & $33.8(0.6)$ \\
\hline \multicolumn{5}{|l|}{ Marital status } \\
\hline Single & 3109 & $26.1(0.5)$ & 3070 & $17.3(0.4)$ \\
\hline Married & 14495 & $69.4(0.5)$ & 17294 & $66.6(0.4)$ \\
\hline Divorced/separated/widowed & 998 & $4.6(0.2)$ & 4917 & $16.1(0.3)$ \\
\hline \multicolumn{5}{|l|}{ Job } \\
\hline Manual & 4811 & $28.7(0.5)$ & 4002 & $18.5(0.3)$ \\
\hline Non-manual & 8952 & $48.2(0.5)$ & 8022 & $31.2(0.4)$ \\
\hline Others & 4839 & $23.1(0.4)$ & 13257 & $50.3(0.4)$ \\
\hline \multicolumn{5}{|l|}{ Chronic disease } \\
\hline 0 & 10267 & $62.1(0.4)$ & 12526 & $54.8(0.4)$ \\
\hline 1 & 4976 & $24.6(0.4)$ & 6691 & $25.7(0.3)$ \\
\hline $2+$ & 3359 & $13.2(0.3)$ & 6064 & $19.5(0.3)$ \\
\hline \multicolumn{5}{|l|}{ Obesity level by BMI } \\
\hline Underweight $\left(<18.5 \mathrm{~kg} / \mathrm{m}^{2}\right)$ & 596 & $3.0(0.2)$ & 1417 & $6.7(0.2)$ \\
\hline Normal/overweight $\left(18.5-<25 \mathrm{~kg} / \mathrm{m}^{2}\right)$ & 11414 & $60.5(0.4)$ & 16524 & $66.0(0.4)$ \\
\hline Obese $\left(25-<30 \mathrm{~kg} / \mathrm{m}^{2}\right)$ & 5944 & $32.2(0.4)$ & 6276 & $22.9(0.3)$ \\
\hline Severe obesity $\left(\geq 30 \mathrm{~kg} / \mathrm{m}^{2}\right)$ & 648 & $4.3(0.2)$ & 1064 & $4.4(0.2)$ \\
\hline \multicolumn{5}{|l|}{ Weight perception } \\
\hline Thin (somewhat/very) & 4051 & $21.3(0.4)$ & 3707 & $13.9(0.3)$ \\
\hline Normal & 7660 & $39.5(0.4)$ & 10246 & $40.6(0.4)$ \\
\hline Somewhat fat & 5922 & $33.2(0.4)$ & 8884 & $35.2(0.4)$ \\
\hline Very fat & 969 & $6.1(0.2)$ & 2444 & $10.2(0.2)$ \\
\hline \multicolumn{5}{|l|}{ Low HRQoL } \\
\hline Lowest quintile of EQ-5D score & 2619 & $10.0(0.3)$ & 5914 & $18.9(0.3)$ \\
\hline
\end{tabular}

*Unweighted frequency.

†Weighted proportion (SE).

‡Equivalised household income was calculated as the total household income divided by the square root of the number of household members; these scores were divided into tertiles.

BMI, body mass index; HRQoL, health-related quality of life; KNHANES, Korean National Health and Nutrition Examination Survey. 
Table 2 Agreement between BMI and weight perception by sex

\begin{tabular}{|c|c|c|c|c|}
\hline \multirow[b]{3}{*}{ Obesity level by BMI } & \multicolumn{4}{|c|}{ Weight perception } \\
\hline & Thin & Normal & Somewhat fat & Very fat \\
\hline & $\mathrm{n}(\%)^{\star}$ & n (\%) & n (\%) & n (\%) \\
\hline Underweight $\left(<18.5 \mathrm{~kg} / \mathrm{m}^{2}\right)$ & $549(3.0)$ & $41(0.2)$ & $4(0.0)$ & $2(0.0)$ \\
\hline Normal/overweight $\left(18.5-<25 \mathrm{~kg} / \mathrm{m}^{2}\right)$ & $3437(18.5)$ & 6304 (33.9) & $1641(8.8)$ & $32(0.2)$ \\
\hline Severe obesity $\left(\geq 30 \mathrm{~kg} / \mathrm{m}^{2}\right)$ & $4(0.0)$ & $22(0.1)$ & $233(1.3)$ & $389(2.1)$ \\
\hline \multicolumn{5}{|l|}{ Women } \\
\hline Underweight $\left(<18.5 \mathrm{~kg} / \mathrm{m}^{2}\right)$ & $1125(4.5)$ & $286(1.1)$ & $5(0.0)$ & $1(0.0)$ \\
\hline Normal/overweight $\left(18.5-<25 \mathrm{~kg} / \mathrm{m}^{2}\right)$ & $2389(9.5)$ & $8859(35.0)$ & $5002(19.8)$ & $274(1.1)$ \\
\hline Obese $\left(25-<30 \mathrm{~kg} / \mathrm{m}^{2}\right)$ & $182(0.7)$ & $1058(4.2)$ & 3625 (14.3) & $1411(5.6)$ \\
\hline $\begin{array}{l}\text { Obesity level by BMI versus weight } \\
\text { perception }\end{array}$ & $\mathbf{n}$ & $\%$ & $\mathbf{n}$ & $\%$ \\
\hline Accurate weight perception (concordance) & 11286 & 60.7 & 14367 & 56.8 \\
\hline \multicolumn{5}{|l|}{ Weight misperception (discordance) } \\
\hline Underestimate & 5050 & 27.2 & 3935 & 15.6 \\
\hline Overestimate & 2266 & 12.2 & 6979 & 27.6 \\
\hline \multicolumn{5}{|l|}{ Agreement } \\
\hline Kappa coefficient & 0.38 & & 0.32 & \\
\hline
\end{tabular}

*Unweighted sample size and total per cent by sex.

$\mathrm{BMI}$, body mass index.

the underweight, obesity and severe obesity groups than in the normal weight group. Likewise, subjects of both sexes who perceived their weight as thin, somewhat fat or very fat had higher ORs for low HRQoL than those who perceived their weight as normal. The ORs of low HRQoL were higher in subjects who underestimated or overestimated their weight than in those who accurately perceived their weight. The association patterns were similar in logit and tobit models in general, although obesity level according to BMI among men had no statistical significance in a tobit model. When we considered the weight perception or misperception in adjusting the obesity level by BMI, the impacts of HRQoL by actual, perceived weights or misperception were similar with separate models in men and women (online supplementary table 2 ).
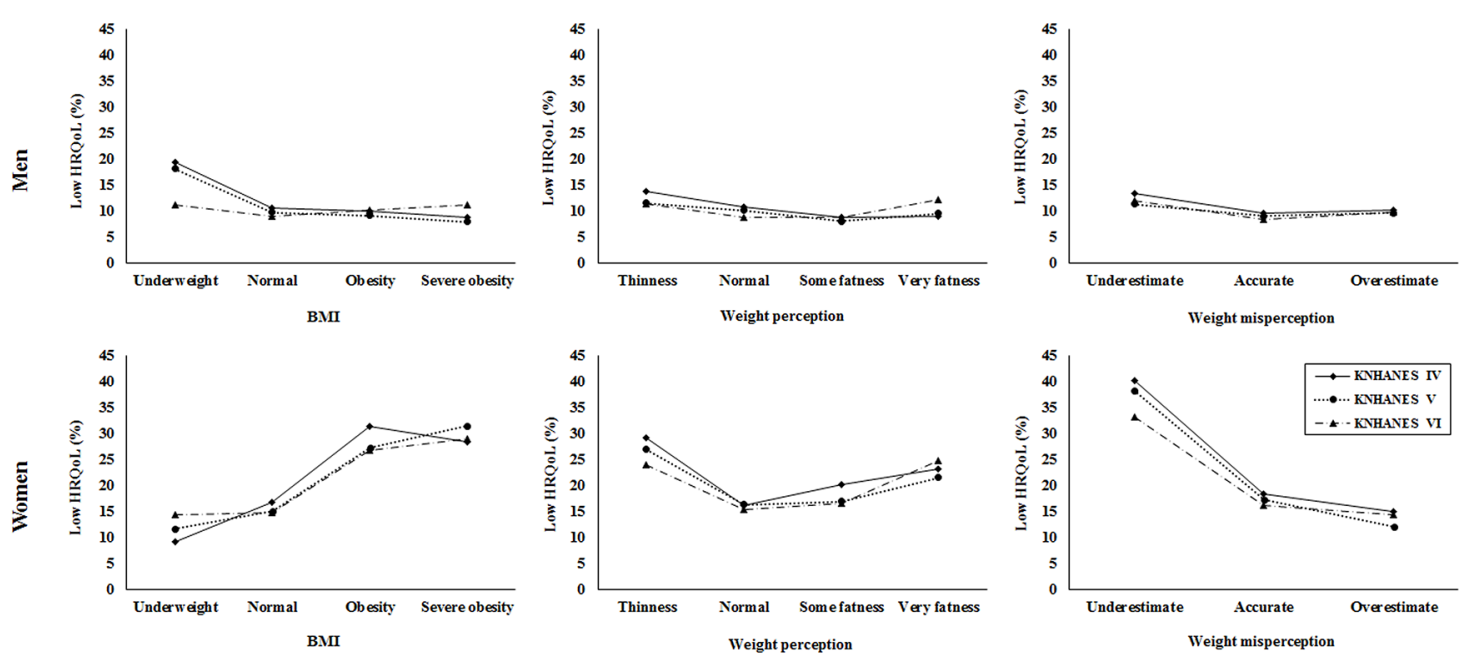

Figure 1 Prevalence of low HRQoL according to BMI, weight perception and weight misperception by survey cycle and sex. BMI, body mass index; HRQoL, health-related quality of life. 
Table 3 Binary and continuous models for EQ-5D scores according to obesity level by BMI, weight perception and weight misperception by sex

\begin{tabular}{llll} 
Univariate & & Multivariate \\
\cline { 1 - 1 } $\begin{array}{lll}\text { Logit modelOR } \\
(95 \% \mathrm{Cl})\end{array}$ & $\begin{array}{l}\text { Tobit model } \\
\text { (SE) }\end{array}$ & $\begin{array}{l}\text { Logit modelOR } \\
(95 \% \mathrm{Cl})\end{array}$ \\
& &
\end{tabular}

Tobit model $\otimes(\mathrm{SE})$

Obesity level by BMI Men

\begin{tabular}{|c|c|c|c|c|}
\hline Underweight $\left(<18.5 \mathrm{~kg} / \mathrm{m}^{2}\right)$ & 1.86 (1.46 to 2.37$)$ & $-0.044^{*}(0.018)$ & 1.58 (1.19 to 2.10$)$ & $-0.013^{*}(0.016)$ \\
\hline Normal/overweight $\left(18.5-<25 \mathrm{~kg} / \mathrm{m}^{2}\right)$ & - & - & - & - \\
\hline Obese $\left(25-<30 \mathrm{~kg} / \mathrm{m}^{2}\right)$ & 0.99 (0.88 to 1.11$)$ & $0.012(0.007)$ & $1.11(0.97$ to 1.26$)$ & $0.005^{\star}(0.007)$ \\
\hline Severe obesity $\left(\geq 30 \mathrm{~kg} / \mathrm{m}^{2}\right)$ & 0.93 (0.69 to 1.25$)$ & $0.006(0.016)$ & 1.51 (1.06 to 2.13$)$ & $-0.022^{*}(0.015)$ \\
\hline \multicolumn{5}{|l|}{ Women } \\
\hline Underweight $\left(<18.5 \mathrm{~kg} / \mathrm{m}^{2}\right)$ & 0.72 (0.58 to 0.88$)$ & $0.033^{\star}(0.010)$ & 1.54 (1.20 to 1.97$)$ & $-0.023^{*}(0.009)$ \\
\hline Normal/overweight $\left(18.5-<25 \mathrm{~kg} / \mathrm{m}^{2}\right)$ & - & - & - & - \\
\hline Obese $\left(25-<30 \mathrm{~kg} / \mathrm{m}^{2}\right)$ & 2.16 (2.00 to 2.33$)$ & $-0.078^{*}(0.005)$ & 1.30 (1.18 to 1.42$)$ & $-0.013^{*}(0.005)$ \\
\hline Severe obesity $\left(\geq 30 \mathrm{~kg} / \mathrm{m}^{2}\right)$ & 2.32 (1.98 to 2.72$)$ & $-0.100^{*}(0.011)$ & 1.59 (1.33 to 1.90$)$ & $-0.038^{*}(0.009)$ \\
\hline \multicolumn{5}{|l|}{ Weight perception } \\
\hline \multicolumn{5}{|l|}{ Men } \\
\hline Thin (somewhat/very) & 1.25 (1.10 to 1.42$)$ & $-0.031^{*}(0.008)$ & 1.31 (1.14 to 1.52$)$ & $-0.027^{\star}(0.008)$ \\
\hline Normal & - & - & - & - \\
\hline Somewhat fat & 0.83 (0.72 to 0.94$)$ & $0.012(0.008)$ & 1.18 (1.01 to 1.37$)$ & $-0.016^{\star}(0.007)$ \\
\hline Very fat & 1.00 (0.79 to 1.28$)$ & $-0.019(0.015)$ & 1.74 (1.32 to 2.29$)$ & $-0.051^{*}(0.014)$ \\
\hline \multicolumn{5}{|l|}{ Women } \\
\hline Thin (somewhat/very) & 1.92 (1.72 to 2.14$)$ & $-0.085^{\star}(0.007)$ & 1.53 (1.34 to 1.76$)$ & $-0.045^{\star}(0.006)$ \\
\hline Normal & - & - & - & - \\
\hline Somewhat fat & 1.15 (1.05 to 1.26$)$ & $-0.023^{*}(0.005)$ & 1.37 (1.23 to 1.52$)$ & $-0.029^{*}(0.004)$ \\
\hline Very fat & 1.55 (1.36 to 1.77$)$ & $-0.066^{\star}(0.008)$ & 1.76 (1.51 to 2.05$)$ & $-0.057^{\star}(0.007)$ \\
\hline \multicolumn{5}{|l|}{ Weight misperception } \\
\hline \multicolumn{5}{|l|}{ Men } \\
\hline Underestimate & 1.38 (1.23 to 1.55$)$ & $-0.033^{\star}(0.007)$ & 1.18 (1.03 to 1.34$)$ & $-0.013^{\star}(0.006)$ \\
\hline Accurate weight perception & - & - & - & - \\
\hline Overestimate & 1.10 (0.93 to 1.30$)$ & $-0.023^{*}(0.010)$ & $1.28(1.05$ to 1.56$)$ & $-0.031^{*}(0.009)$ \\
\hline \multicolumn{5}{|l|}{ Women } \\
\hline Underestimate & 2.87 (2.61 to 3.15$)$ & $-0.129^{*}(0.007)$ & 1.18 (1.05 to 1.32$)$ & $-0.020^{*}(0.006)$ \\
\hline Accurate weight perception & - & - & - & - \\
\hline Overestimate & 0.76 (0.69 to 0.83$)$ & $0.012^{*}(0.005)$ & 1.15 (1.04 to 1.28$)$ & $-0.022^{*}(0.005)$ \\
\hline
\end{tabular}

${ }^{*} \mathrm{p}<0.05$.

†Adjusted for time of survey cycle, age, marital status, job, household income, education, and number of chronic diseases. OR for lowest quintile of $\mathrm{EQ}-5 \mathrm{D}$ scores.

BMI, body mass index.

We examined the association between weight misperception and HRQoL after stratification by BMI category (table 4). Both underestimation and overestimation of weight had a significantly negative impact on HRQoL in the subgroup of 'normal/overweight' in logit and tobit models. In the subgroup of 'obesity', only weight overestimation had an adverse effect on HRQoL in both sexes in the tobit model, with statistical significance. Although no statistical significance was found in the logit model, similar association patterns were observed. However, no negative impact on HRQoL was observed in the subgroups of 'underweight' and 'severe obesity' according to BMI level.

\section{DISCUSSION}

This study examined the impact of obesity level according to BMI, weight perception and weight misperception on HRQoL. Subjects with underweight or obesity by BMI were more likely to report low HRQoL. Similarly, subjects 


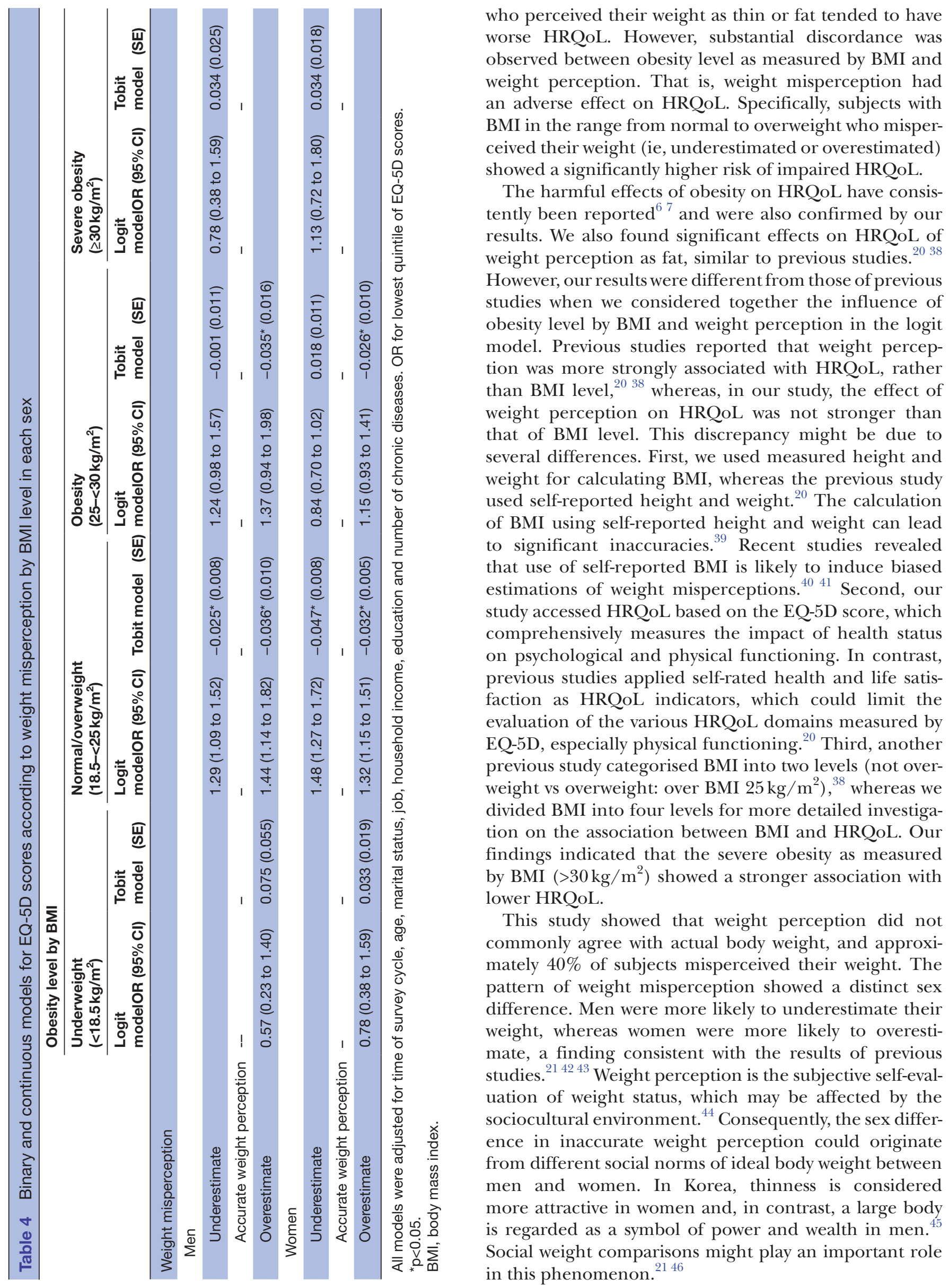


Although our findings showed typically different patterns of weight misperception between sexes, the negative effect of weight misperception on HRQoL was shown for both sexes. Underestimation or overestimation of weight may cause unhealthy dietary intake, unhealthy behaviours and psychological distress. ${ }^{10-13}$ 15-19 These findings support the hypothesis that weight misperception, including underestimation and overestimation, could have an adverse effect on HRQoL, directly or indirectly. Previous studies have also demonstrated significantly negative effects of overestimation of weight on HRQoL. ${ }^{25-27}$ However, several studies showed different results, either a positive association ${ }^{28}$ or non-significant association ${ }^{20}$ between underestimated and overestimated weight misperception and HRQoL. These studies involved self-reported BMI measures, ${ }^{20}$ different HRQoL tools (ie, Pediatric Quality of Life Inventory(PedsQL) or life satisfaction $)^{20} 28$ or adolescent subjects. ${ }^{25-28}$ Thus, direct comparison of those studies with our findings should be performed with caution.

In a subgroup analysis by BMI level, weight misperception of subjects with BMI ranges from normal to overweight had a negative impact on HRQoL as well. However, there was no significant association between weight misperception and HRQoL in underweight and severely obese subjects. Weight discrimination is prevalent in many societies. ${ }^{47-49}$ If underweight or obesity is a stigmatised condition, this may lead people of normal weight who misperceive their weight to experience unnecessary psychological distress regarding weight and employ inadequate coping responses. ${ }^{50} 51$ Moreover, self-stigmatisation in obesity has been associated with future weight gain. ${ }^{16}{ }^{17}$ Likewise, obese people who perceive their weight as 'very fat' may experience more stress compared with obese people who identify their weight as 'somewhat fat'. Although accurate weight perception in obese people could encourage healthy weight, too much concern about their weight may cause adverse effects on HRQoL. However, people with underweight or severe obesity were more likely to suffer from existing chronic conditions ${ }^{12}$; thus, the effect of weight misperception might be attenuated among these groups. Moreover, misperception in underweight or severely obese people may provide comfort in regard to mental health, ${ }^{20} 28$ even though the other harmful effects of obesity continue to exist.

The present study highlighted the significantly adverse effect of weight misperception on HRQoL. Considering that a large number of people fail to recognise their actual weight status, we suggest that public health efforts, such as publicising criteria for healthy weight, are indicated. Clinical practitioners should also inform patients, both with and without obesity, of their accurate weight status. This was the first Asian study to examine the impact of weight misperception, including both underestimation and overestimation, on HRQoL for individuals of all BMI ranges. The advantage of this study was that it investigated the association between weight misperception and HRQoL through analysis of nationally representative data with a large sample size. However, this study has several limitations. First, the cross-sectional design limits causal inferences from our results. Second, other confounding factors, such as unmeasured illness and psychological conditions, could affect weight misperception and HRQoL. Third, the effect size of weight misperception was quite small. For example, people who underestimated or overestimated their weight had an approximately $20 \%-50 \%$ increased risk of low HRQoL compared with people who perceived their weight correctly. This result was obtained after adjusting for the influences of age, chronic disease and socioeconomic status. Therefore, the effect of weight misperception was non-negligible considering the strong effect of age and chronic disease on health and quality of life. Fourth, although we defined low HRQoL as the lowest quintile of the EQ-5D score, generally there was not a clear cut-off point for low HRQoL. The EQ-5D score showed a left skewed distribution with a ceiling score of 1 . There have been several methodological approaches to analysis of the EQ-5D index score including quantile regression, tobit model and Censored least absolute deviations(CLAD) model. ${ }^{52} 53$ Unfortunately, statistical software has not yet supported the quantile regression or CLAD model for complex survey data. When the complex sampling design is not applied properly, SEs could be overestimated or underestimated. Therefore, we have considered the EQ-5D scores as right-censored data and performed tobit regression modelling taking into account the complex survey design using STATA.

\section{CONCLUSION}

The findings of this study provide important insights into obesity level by BMI, weight perception and HRQoL for adults. Underweight and obesity, as measured by BMI, were risk factors for low HRQoL, after adjusting for weight perception and various covariates. Inaccurate weight perceptions, including both underestimation and overestimation, were significantly associated with low HRQoL. In subgroup analysis, our results showed that subjects with normal BMI, who perceived their weight as thin or fat, had significantly lower HRQoL. Our findings suggest that public health strategies should promote healthy weight and focus on fostering accurate weight perception among the population.

Correction notice This paper has been amended since it was published Online First. Owing to a scripting error, some of the publisher names in the references were replaced with 'BMJ Publishing Group'. This only affected the full text version, not the PDF. We have since corrected these errors and the correct publishers have been inserted into the references.

Contributors J-WK designed the study and supervised all procedure; SP analysed data and wrote the manuscript; and SL and JH revised the manuscript. All authors agreed to accept equal responsibility for the accuracy of the content of the paper.

Funding This research was supported by a grant of the Korea Health Technology R\&D Project through the Korea Health Industry Development Institute (KHIDI), 
funded by the Ministry of Health \& Welfare, Republic of Korea (grant number: HC15C1322)

Competing interests None declared.

Patient consent Yes.

Ethics approval By the ethics committee of the KCDC (2008-04EXP-01-C, 2009-01CON-03-2C and 2010-02CON-21-C).

Provenance and peer review Not commissioned; externally peer reviewed.

Data sharing statement Data are available through the website of the KCDC. https://knhanes.cdc.go.kr.

Open Access This is an Open Access article distributed in accordance with the Creative Commons Attribution Non Commercial (CC BY-NC 4.0) license, which permits others to distribute, remix, adapt, build upon this work non-commercially, and license their derivative works on different terms, provided the original work is properly cited and the use is non-commercial. See: http://creativecommons.org/ licenses/by-nc/4.0/

(c) Article author(s) (or their employer(s) unless otherwise stated in the text of the article) 2017. All rights reserved. No commercial use is permitted unless otherwise expressly granted.

\section{REFERENCES}

1. Kelly T, Yang W, Chen CS, et al. Global burden of obesity in 2005 and projections to 2030. Int J Obes 2008;32:1431-7.

2. Kopelman P. Health risks associated with overweight and obesity. Obes Rev 2007;8 Suppl 1:13-17.

3. Moore CJ, Cunningham SA. Social position, psychological stress, and obesity: a systematic review. J Acad Nutr Diet 2012;112:518-26.

4. Atlantis E, Baker M. Obesity effects on depression: systematic review of epidemiological studies. Int J Obes 2008;32:881-91.

5. Gariepy G, Nitka D, Schmitz N. The association between obesity and anxiety disorders in the population: a systematic review and metaanalysis. Int J Obes 2010;34:407-19.

6. Fontaine KR, Barofsky I. Obesity and health-related quality of life. Obes Rev 2001;2:173-82.

7. Sarwer DB, Lavery M, Spitzer JC. A review of the relationships between extreme obesity, quality of life, and sexual function. Obes Surg 2012;22:668-76.

8. Driscoll S, Gregory DM, Fardy JM, et al. Long-term health-related quality of life in bariatric surgery patients: a systematic review and meta-analysis. Obesity 2016;24:60-70.

9. Andersen JR, Aasprang A, Karlsen TI, et al. Health-related quality of life after bariatric surgery: a systematic review of prospective longterm studies. Surg Obes Relat Dis 2015;11:466-73.

10. Duncan DT, Wolin KY, Scharoun-Lee M, et al. Does perception equal reality? Weight misperception in relation to weight-related attitudes and behaviors among overweight and obese US adults. Int J Behav Nutr Phys Act 2011;8:20.

11. Forman MR, Trowbridge FL, Gentry EM, et al. Overweight adults in the United States: the behavioral risk factor surveys. Am J Clin Nutr 1986;44:410-6.

12. Skinner AC, Weinberger M, Mulvaney S, et al. Accuracy of perceptions of overweight and relation to self-care behaviors among adolescents with type 2 diabetes and their parents. Diabetes Care 2008;31:227-9.

13. Edwards NM, Pettingell S, Borowsky IW. Where perception meets reality: self-perception of weight in overweight adolescents. Pediatrics 2010;125:e452-e458.

14. Talamayan KS, Springer AE, Kelder SH, et al. Prevalence of overweight misperception and weight control behaviors among normal weight adolescents in the United States. ScientificWorldJournal 2006;6:365-73.

15. Sonneville KR, Thurston IB, Milliren CE, et al. Weight misperception among young adults with overweight/obesity associated with disordered eating behaviors. Int J Eat Disord 2016;49:937-46.

16. Robinson E, Hunger JM, Daly M. Perceived weight status and risk of weight gain across life in US and UK adults. Int $J$ Obes 2015;39:1721-6.

17. Sutin AR, Terracciano A. Body weight misperception in adolescence and incident obesity in young adulthood. Psychol Sci 2015;26:507-11.

18. Seo J, Ma H, Kim S, et al. Effects of the difference between actual body condition and body image perception on nutrient intake, weight control and mental health in korean adults: based on the 5th
Korea National Health and Nutrition Examination Survey. Journal of Nutrition and Health 2016;49:153-64.

19. Lee KM, Seo MS, Shim JY, et al. Body weight status misperception and its association with weight control behaviours, depressive mood and psychological distress in nulliparous normal-weight young women. Ann Hum Biol 2015;42:528-32.

20. Herman KM, Hopman WM, Rosenberg MW. Self-rated health and life satisfaction among canadian adults: associations of perceived weight status versus BMI. Qual Life Res 2013;22:2693-705.

21. Burke MA, Heiland FW, Nadler CM. From "overweight" to "about right": evidence of a generational shift in body weight norms. Obesity 2010;18:1226-34.

22. Kim S, So WY. Secular trends in the prevalence of weight misperception among Korean adults, 2001-2013. Obes Res Clin Pract 2016 (ahead of print 14 January 2016).

23. Wardle J, Haase AM, Steptoe A. Body image and weight control in young adults: international comparisons in university students from 22 countries. Int J Obes 2006;30:644-51.

24. Gillen MM, Lefkowitz ES. Body size perceptions in racially/Ethnically diverse men and women: implications for Body image and SelfEsteem. N Am J Psychol 2011;13:447-67.

25. Southerland J, Wang L, Richards K, et al. Misperceptions of overweight: associations of weight misperception with health-related quality of life among normal-weight college students. Public Health Rep 2013;128:562-8.

26. Farhat T, lannotti RJ, Summersett-Ringgold F. Weight, Weight Perceptions, and Health-Related Quality of Life Among a National Sample of US Girls. J Dev Behav Pediatr 2015;36:313-23.

27. Southerland JL, Wang L, Slawson DL. Weight Misperception and Health-Related Quality of Life in Appalachian Adolescents in the United States. Matern Child Health J 2017;21:168-76.

28. Hayward J, Millar L, Petersen S, et al. When ignorance is bliss: weight perception, body mass index and quality of life in adolescents. Int J Obes 2014;38:1328-34.

29. Kweon S, Kim Y, Jang MJ, et al. Data resource profile: the Korea National Health and Nutrition Examination survey (KNHANES). Int $J$ Epidemiol 2014;43:69-77.

30. Kim MH, Cho YS, Uhm WS, et al. Cross-cultural adaptation and validation of the Korean version of the EQ-5D in patients with rheumatic diseases. Qual Life Res 2005;14:1401-6.

31. Lee YK, Nam HS, Chuang LH, et al. South Korean time trade-off values for EQ-5D health states: modeling with observed values for 101 health states. Value Health 2009;12:1187-93.

32. Ko HY, Lee JK, Shin JY, et al. Health-Related Quality of Life and Cardiovascular Disease Risk in Korean Adults. Korean J Fam Med 2015;36:349-56.

33. Choi YJ, Lee MS, An SY, et al. The Relationship between Diabetes Mellitus and Health-Related Quality of Life in Korean Adults: The Fourth Korea National Health and Nutrition Examination Survey (2007-2009). Diabetes Metab J 2011;35:587-94.

34. Park Y, Shin JA, Yang SW, et al. The Relationship between Visual Impairment and Health-Related Quality of Life in Korean Adults: The Korea National Health and Nutrition Examination Survey (2008-2012). PLoS One 2015;10:e0132779.

35. Who/IASO/IOTF. The Asia-Pacific perspective: redefining obesity and its treatment. Health Communications Australia Pty Ltd, 2000.

36. Choi Y, Choi E, Shin D, et al. The Association between Body Weight Misperception and Psychosocial Factors in Korean Adult Women Less than 65 Years Old with Normal Weight. J Korean Med Sci 2015;30:1558-66.

37. Byeon $\mathrm{H}$. Association between Weight Misperception patterns and depressive symptoms in Korean young adolescents: national CrossSectional Study. PLoS One 2015;10:e0131322.

38. Burns CM, Tijhuis MA, Seidell JC. The relationship between quality of life and perceived body weight and dieting history in Dutch men and women. Int $J$ Obes Relat Metab Disord 2001;25:1386-92.

39. Engstrom JL, Paterson SA, Doherty A, et al. Accuracy of selfreported height and weight in women: an integrative review of the literature. J Midwifery Womens Health 2003;48:338-45.

40. Robinson $\mathrm{E}$, Oldham $\mathrm{M}$. Weight status misperceptions among UK adults: the use of self-reported vs. measured BMI. BMC Obes 2016;3:21.

41. Haghighian Roudsari A, Vedadhir A, Kalantari N, et al. Concordance between self-reported body mass index with weight perception, selfrated health and appearance satisfaction in people living in Tehran. $J$ Diabetes Metab Disord 2015;15:22. 
42. Paeratakul S, White MA, Williamson DA, et al. Sex, race/ethnicity, socioeconomic status, and $\mathrm{BMI}$ in relation to self-perception of overweight. Obes Res 2002;10:345-50.

43. Yaemsiri S, Slining MM, Agarwal SK. Perceived weight status, overweight diagnosis, and weight control among US adults: the NHANES 2003-2008 Study. Int J Obes 2011;35:1063-70.

44. Gillen MM, Lefkowitz ES. Body size perceptions in racially/Ethnically diverse men and women: implications for Body image and SelfEsteem. N Am J Psychol 2011;13:447-67.

45. Joh HK, Oh J, Lee HJ, et al. Gender and socioeconomic status in relation to weight perception and weight control behavior in Korean adults. Obes Facts 2013;6:17-27.

46. Fitzsimmons-Craft EE, Bardone-Cone AM, Wonderlich SA, et al. The relationships among social comparisons, body surveillance, and body dissatisfaction in the natural environment. Behav Ther 2015;46:257-71.
47. Andreyeva T, Puhl RM, Brownell KD. Changes in perceived weight discrimination among Americans, 1995-1996 through 2004-2006. Obesity 2008;16:1129-34.

48. Gee GC, Ro A, Gavin A, et al. Disentangling the effects of racial and weight discrimination on body mass index and obesity among Asian Americans. Am J Public Health 2008;98:493-500.

49. Sutin AR, Terracciano A. Perceived weight discrimination and obesity. PLoS One 2013;8:e70048.

50. Tomiyama AJ. Weight stigma is stressful. A review of evidence for the cyclic obesity/Weight-Based stigma model. Appetite 2014;82:8-15.

51. Schvey NA, Puhl RM, Brownell KD. The impact of weight stigma on caloric consumption. Obesity 2011;19:1957-62.

52. Li L, Fu AZ, Az F. Some methodological issues with the analysis of preference-based EQ-5D index score. Health Services and Outcomes Research Methodology 2009;9:162-76.

53. Sullivan PW, Ghushchyan V. Mapping the EQ-5D index from the SF12: us general population preferences in a nationally representative sample. Med Decis Making 2006;26:401-9. 